\title{
Specimen Preparation of Difficult Materials for EBSD Characterization
}

\author{
Ron Witt,* M. M. Nowell,** \\ * EBSD Analytical, Lehi, UT 84043 \\ ** EDAX/TSL, Draper, UT 84020
}

Electron backscatter diffraction (EBSD) is a materials characterization technique that has seen many improvements both in the software and hardware over the years. With all of the improvements that have been made with the detection and analysis of EBSD patterns, sample preparation is still the key to obtaining high quality data.

EBSD patterns are generated from the top 10 to $50 \mathrm{~nm}$ of the surface. Any deformation, oxide layers or other anomalies will degrade the quality of the pattern. It is critical to have a well-polished, deformation free surface to yield the best results. For many materials, this can be accomplished with a basic mechanical polishing procedure. Chemical and/or electro polishing can also be useful, but care must be taken not to over etch the sample, as the topography often introduced using these methods can negatively affect the EBSD pattern. Our focus will be on basic mechanical polishing techniques. Once the surface is ground planar using 240 grit $\mathrm{SiC}$ paper, further grinding is carried out using 320, 400, 600, 800, and 1200 grit SiC paper, each for about 30 seconds. After grinding, polishing with $1 \mu \mathrm{m}$ alumina or diamond suspension for 5 to 10 minutes is followed by a $0.3 \mu \mathrm{m}$ suspension, again for 5 to 10 minutes. Diamond is preferred if edge retention is critical, or if multiple phases are present. The final polish usually consists of a 0.05 or $0.02 \mu \mathrm{m}$ colloidal silica solution. Colloidal silica is a chemically aggressive suspension which provides a chemicalmechanical polish, giving excellent results for EBSD analysis. This final step can range from a few minutes to several hours, depending on the material. Softer materials generally require more polishing time, and do better with smaller abrasives.

There are certain materials where the above procedure does not work. Magnesium and its alloys are attacked by water, so a mixture of glycerin and alcohol can be used during the grinding phases. Fine polishing is done using a glycol based solution of $1 \mu \mathrm{m}$ alumina followed by a $0.02 \mu \mathrm{m}$ alumina. Usually the EBSD patterns are still not very sharp at this point. Ion-etching Mg samples for several hours at a high tilt and relatively low current $(2.5 \mathrm{kV})$ works well as a final polish. Figure 1 shows an EBSD pattern from a $\mathrm{Mg}$ alloy after ion etching for 8 hours.

Another difficult material to polish is titanium. Titanium is extremely ductile, making it prone to mechanical deformation and is easily scratched. Grinding should be kept to a minimum, and is done using SiC paper, especially when polishing pure and softer titanium. After grinding with either 240 or 320 grit SiC paper, polishing is followed with a 7-9 $\mu \mathrm{m}$ diamond suspension for about 10 minutes. The final, chemical-mechanical polish involves a mixture of colloidal silica and hydrogen peroxide (30\%). Figure 2 shows EBSD results from a titanium sample before the chemical-mechanical polish, and figure 3 shows the results after the polish. What appears as small dark regions are indexed as cubic EBSD patterns. The final chemical-mechanical polish removes this phase, revealing the true hexagonal microstructure. 


\section{References}

[1] M.M Nowell et al., Microsc. Microanal. 11(Suppl. 2) (2005) 504.

[2] G.F. Vander Voort, Metallography Principles and Practice. ASM International, Ohio, 1999

[3] D. Katrakova and F. Mucklich, Practical Metallographie, 38 (2001) 547

[4] C. Boehlert et al., Scripta Materialia, 45 (2001) 1107.

[5] M.M. Nowell et al., Microsc. Microanal. 15(Suppl. 2) (2009) 780.

[6] B. Taylor, Metallographic Preparation of Titanium, Struers Application Notes, 2010

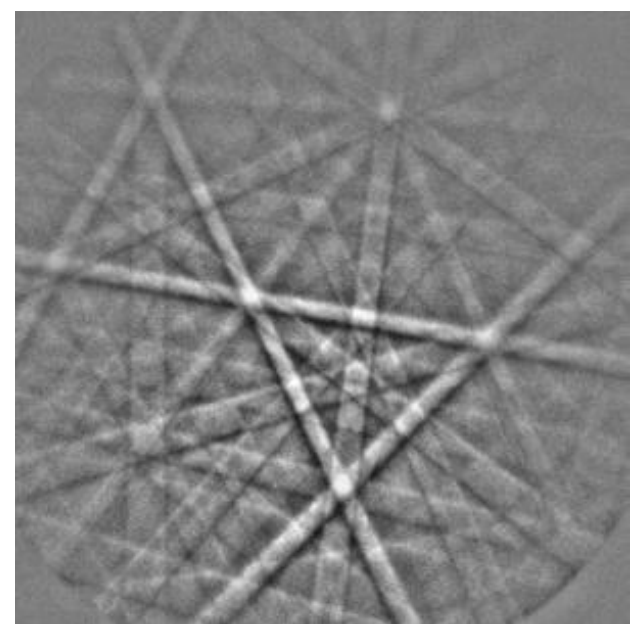

FIG. 1. EBSD pattern from a Mg alloy. The sample was polished to $0.02 \mu \mathrm{m}$ colloidal alumina for 5 hours followed by an ion etch at $2.5 \mathrm{kV}$ for 8 hours.

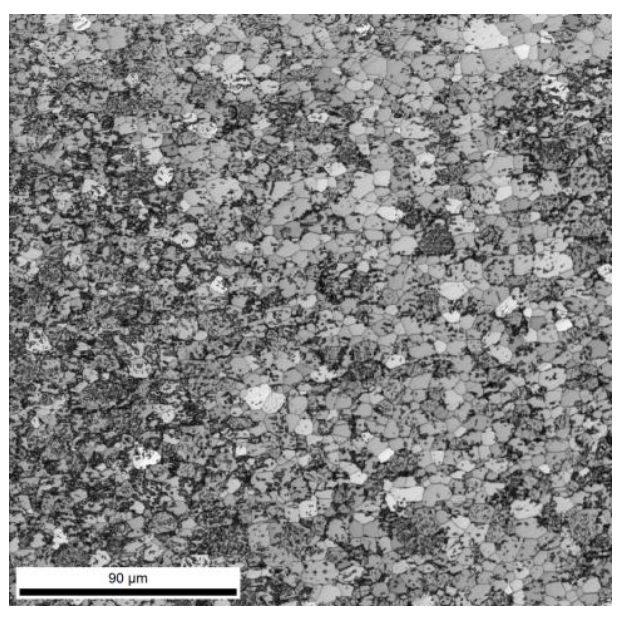

FIG. 2. EBSD map showing results on Ti before chemical-mechanical polish

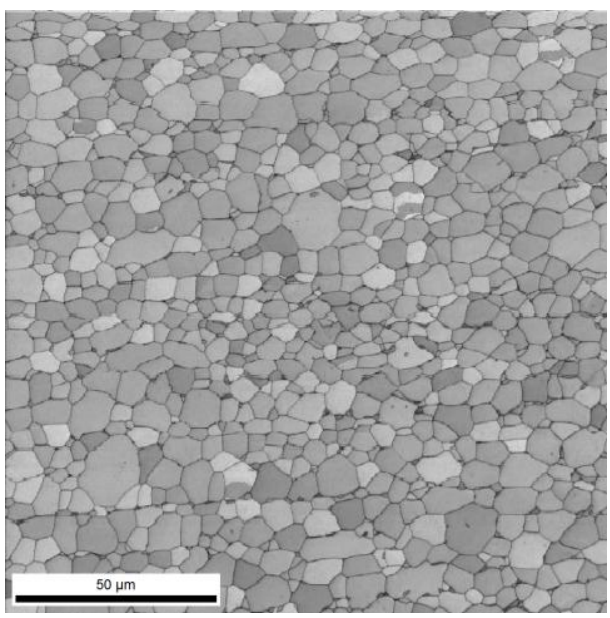

FIG. 3. EBSD map showing results on Ti after chemical-mechanical polish 